\title{
A Possible Destruction of SARS-CoV-2 by a Cylindrical Probe Coated with the Graphene Oxide: A Thermal-based Model
}

\author{
Tony Sumaryada ${ }^{1, *} \mathbb{D}$, Fajrul Kamil Ramadhan ${ }^{1}$ \\ 1 Computational Biophysics and Molecular Modeling Research Group (CBMoRG), Department of Physics, IPB University, \\ Jalan Meranti Kampus IPB Dramaga Bogor 16680, Indonesia \\ * Correspondence: tsumaryada@apps.ipb.ac.id;
}

Scopus Author ID 55872955200

Received: 18.12.2020; Revised: 20.01.2021; Accepted: 24.01.2021; Published: 31.01.2021

\begin{abstract}
In this paper, the possible use of graphene oxide (GO) to destroy SARS-CoV-2 of COVID19 is modeled. A molecular docking approach was first conducted to estimate the binding energy of GO with the spike glycoprotein of SARS-CoV-2 virus (SGCoV). A simple space-limited geometry model is used to set up the maximum limit of SARS-CoV-2 that can be absorbed on the GO surface. Using the GO surface as a hotbed for virus destruction and utilizing the unique properties of GO (the molecular weight, the area to mass ratio, and the specific heat), we build a thermal-based model to explore the possibility of destroying the adsorbed SARS-CoV-2 on the GO-coated cylindrical probe. A hypothetical design of a medical device that could benefit from this model is also proposed here.
\end{abstract}

Keywords: COVID-19; graphene oxide; molecular docking; thermal-based model; spike glycoprotein.

(C) 2021 by the authors. This article is an open-access article distributed under the terms and conditions of the Creative Commons Attribution (CC BY) license (https://creativecommons.org/licenses/by/4.0/).

\section{Introduction}

The ongoing COVID-19 pandemic has shocked the world with a staggering number of infected people and casualties. As of December 27, 2020, about 80,818,467 people have been infected in 218 countries with 1,766,847 deaths, based on the data from worldometer (https://www.worldometers.info/coronavirus/\#countries). Massive effort and intensive research are taking place all around the world to stop and eradicate this pandemic. The use of some drugs like chloroquine phosphate and hydroxychloroquine [1-3], and some protease inhibitors such as lopinavir, ritonavir, darunavir, remdesivir, favipiravir, and some herbal compounds [4-9] are some of the ongoing research in this field. Among other progress, the ability to accurately and effectively detect and destroy the SARS-CoV-2 earlier plays a crucial role in reducing the pandemic's spreading. It is very important to develop a medical device that is capable of destroying the SARS-CoV-2 effectively. Since very limited information is available right now regarding the precise mechanism of the COVID-19 infection to the body, a new and creative model based on the actual physical interaction will help us find a way to eradicate this pandemic.

The newly deposited structure of spike glycoprotein of SARS-CoV-2 (SGCoV) by [10] has ignited the in-silico research to find the drug for eradicating the COVID-19. This protein structure of SGCoV can be accessed in protein data bank (www.rcsb.org) with the PDB ID $6 \mathrm{VSB}$. This spike glycoprotein of SARS-CoV-2 will interact with the ACE2 receptor through 
a "lock and key" mechanism before entering the cell and hijacking the cell replication process [11]. Some groups have already reported their preliminary results on the roles of SGCoV in finding the drugs for COVID-19 [12-15].

Graphene is assumed as a two-dimensional (2D) object that is often named as the future material due to its superior physical properties such as high carrier mobility, high thermal conductivity, high mechanical strength, high optical transparency, large surface area, low toxicity level, and high level of biocompatibility [16-25]. One particular type of graphene materials is graphene oxide (others are pristine graphene and reduced graphene oxide), which posses promising potentials in a biomedical application such as biosensors, bioimaging, photothermal therapy, drug nanocarrier, anti-microbial agent, and antiviral agent [26-33]. Several reports have shown that graphene oxide can inhibit and suppress some viruses' replication process, such as herpes virus and SARS-CoV-2 in their corresponding targeted cells [33-38].

Molecular docking is a computational approach to study the interaction and bonding between molecules (protein, enzyme, and ligand). By assuming biomolecule and ligand as a physical entity that obeys the physics laws (electrostatic and thermodynamics), we can predict the interaction strength, distance, and position (pose) of ligand and biomolecule in a particular complex. Combined with proper statistical analysis and optimization strategy, a docking score will be produced. This docking score shows the ligand's binding spontaneity on a protein/enzyme to control particular biochemistry or biophysical process. Molecular docking has been used in predicting the biosensing potential of some mesoscopic carbon nanostructures such as graphene, carbon nanotubes, quantum dots, and fullerenes [26, 39-42]. Those carbon nanostructures' ability in adsorbing the biomolecules or a particular chemical compound can be used for biosensing application and medical treatment, such as photothermal or photodynamic therapy. The use of nanotechnology for combating COVID-19, such as a rapid detection kit, magnetic nanoparticles, and viral RNA, and a spray-based coating for personal protective equipment (PPE) is currently investigated [43].

Some possible uses of graphene materials for fighting COVID-19 have been proposed by [44]. Those examples including the development of graphene-based sensors embedded in a fabric (or textile) and the use of graphene as a coating material for medical devices and facemask. Graphene materials can also be used to trap the virus for a further thermal or optical treatment for SARS-CoV-2 inactivation. The superior thermal conductivity of graphene materials might help a rapid heat delivery to destroy the SARS-CoV-2. The low toxicity level and the high biocompatibility level of GO also ensure its safe use in medical treatment. In that context, our research aims to model the adsorption and inactivation of the SARS-CoV-2 by GO sheet and explore the possibility of using GO in destroying the SARS-CoV-2 via a thermalbased model. A hypothetical design of the destruction of SARS-CoV-2 by utilizing the thermal properties of $\mathrm{GO}$ is also proposed in this paper.

\section{Materials and Methods}

The docking simulation's target (receptor) is a spike glycoprotein of SARS-CoV-2 in the prefusion conformation, which is available in Protein Data Bank with PDB ID 6VSB and can be downloaded from www.rcsb.org. This SGCoV protein must be cleaned from water molecules and its inhibitor (NAG) using Chimera software [45]. The 2D structure of graphene oxide can be found in the PubChem database (CID:124202900) in the SDF file. This 2D structure must be converted into a 3D structure using an online 3D structure generator at this 
website https://www.mn-am.com/online_demos/corina_demo. The 3D SDF file then converted into a PDB file using Chimera software. Using Autodock tools ADT 1.5.6, the additional polar hydrogen atoms and Gasteiger charges were introduced to the ligand and receptor. The final structure of ligand and receptor then saved in PDBQT format [46].

The semi-targeted docking simulations were performed using the AutoDock Vina program [47], with a grid box almost covering the whole front side of the SGCoV structure. The grid box's size was fixed to $\mathrm{x}=74 \AA \mathrm{A}, \mathrm{y}=76 \AA$, and $\mathrm{z}=52 \AA$, while the center point was set to $\mathrm{x}=227.173, \mathrm{y}=224.184, \mathrm{z}=156.425$. The simulations were performed on a laptop with Intel Core i7-7700 HQ CPU, 2.80 GHz processor, and 8 GB of RAM, under Windows 10 Home and 64-bit platform. The cartoon representation of the 6VSB target and GO sheet are shown in Figure 1.

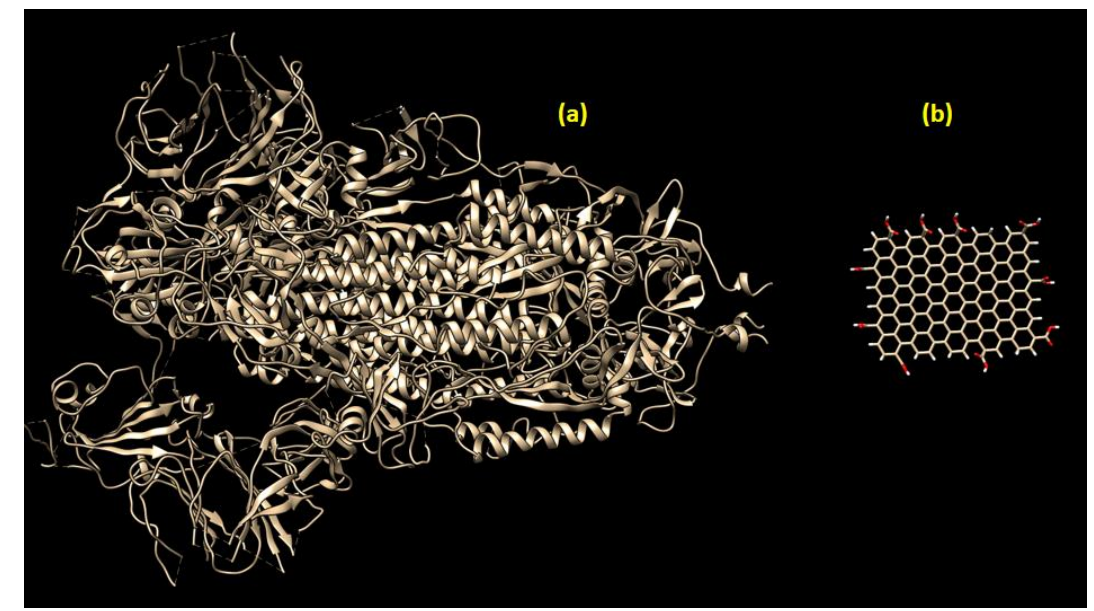

Figure 1. (a) The structure of spike glycoprotein of COVID-19 (6VSB). (b) Graphene Oxide. Note: figures are not to scale.

\section{Results and Discussion}

\subsection{The binding of SGCoV with GO.}

The antiviral activity of GO sheet might come from the interaction between the viruses and the negatively charged GO sheet. In our docking results, the binding affinity of spike glycoprotein of COVID-19 with graphene oxide was concentrated in four regions or clusters, as seen in Table 1 and Figure 2. About 55\% of GO-SGCoV binding had taken place in cluster one, while the binding probabilities in cluster two, three, and four are only 30\%, 10\%, and 5\%, respectively. The strongest binding can be found in mode number one in cluster one, with $\Delta \mathrm{G}$ $=-12.3 \mathrm{kcal} / \mathrm{mol}$. The inhibition of the front end of SGCoV by the sharp corner of GO sheet demonstrated by $[34,48]$ is also found in our docking results. We have $65 \%$ (from clusters 1 and 3 ) of the binding modes found in the front end of SGCoV. The GO sheets occupy the binding sites of NAG (N-Acetylglucosamine, the natural ligand of SGCoV) on SGCoV. In this case, a GO-coated cylindrical probe can be used to adsorb or trap the SARS-CoV-2 for further action, such as heat treatment or irradiation to destroy the viruses. For example, the GO sheet can be deposited on the surface of cylindrical steel by electrophoretic deposition, as demonstrated by [49]. 
Table 1. The binding affinity of SGCoV on GO.

\begin{tabular}{l|l|l} 
Cluster number & Binding mode & Binding mode with the lowest $\Delta \mathbf{G}$ \\
\hline 1 & $1,4,5,6,7,8,9,10,16,17,18$ & Mode $1(-12.3 \mathrm{kcal} / \mathrm{mol})$ \\
\hline 2 & $2,3,12,13,15,19$ & Mode $2(-12.2 \mathrm{kcal} / \mathrm{mol})$ \\
\hline 3 & 11,14 & Mode $11(-10.9 \mathrm{kcal} / \mathrm{mol})$ \\
\hline 4 & 20 & Mode $20(-10.2 \mathrm{kcal} / \mathrm{mol})$
\end{tabular}

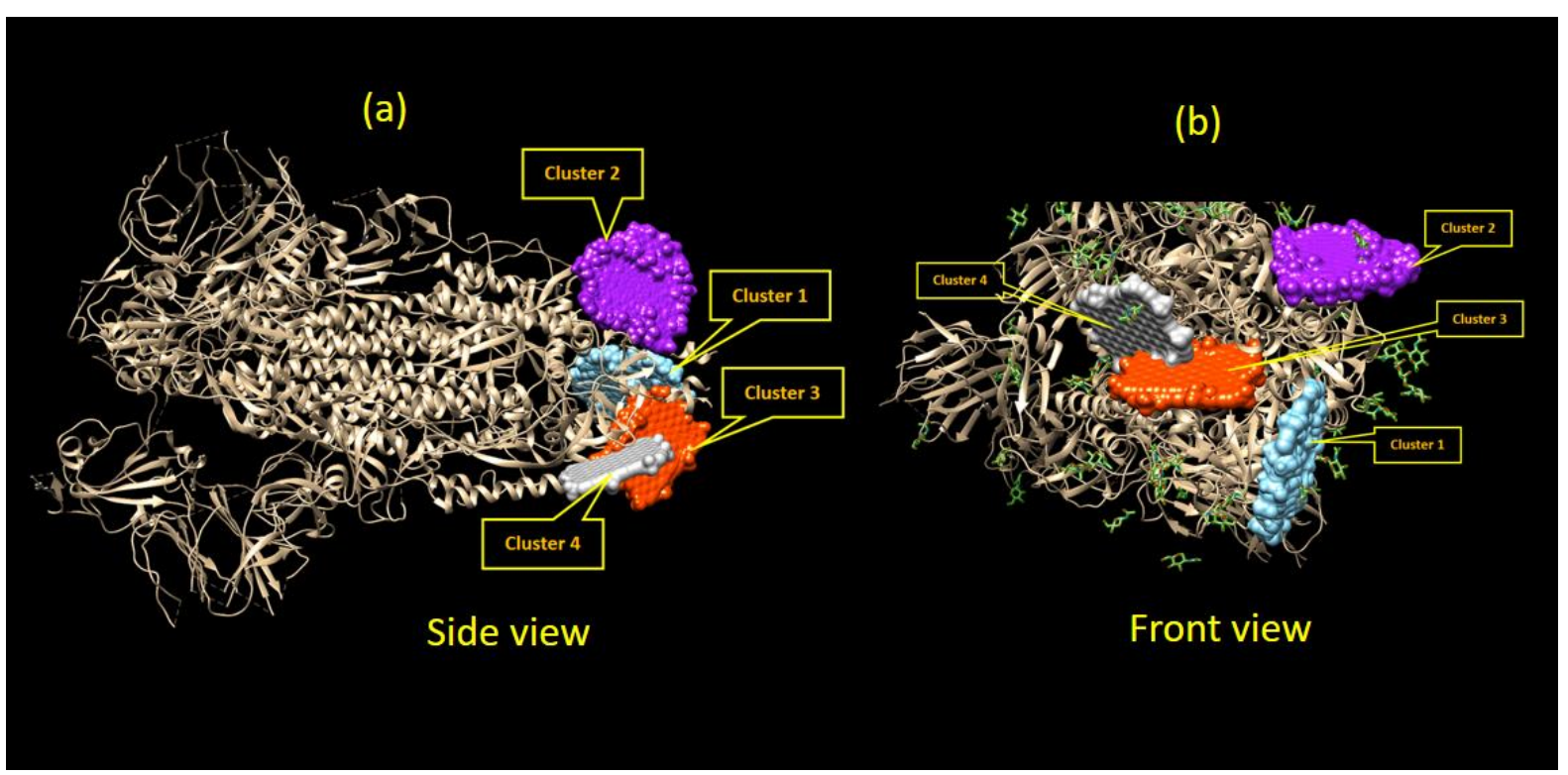

Figure 2. The binding interaction of spike glycoprotein of COVID-19 and GO sheet as viewed from (a) the side view and (b) the front view.

3.2. A thermal-based model of the destruction of SARS-CoV-2 by utilizing the thermal properties of $G O$.

Utilizing some properties of GO, i.e., the area to mass ratio, $\beta=2418 \mathrm{~m}^{2} / \mathrm{g}[50]$ and the molecular weight of the GO, $M_{w}=2014.8 \mathrm{~g} / \mathrm{mol}$, we can count the number of GO sheet available theoretically on a surface of a particular GO-coated cylindrical probe as illustrated in Figure 3 by

$$
N_{G O}=\frac{N_{A} \cdot A}{M_{w} \cdot \beta}
$$

where $N_{A}$ is the Avogadro number $\left(N_{A}=6.022 \times 10^{23}\right.$ molecule $\left./ \mathrm{mol}\right)$, and $\mathrm{A}$ is the area of GO sheet. Assuming a GO-coated cylindrical probe with a diameter of $0.5 \mathrm{~cm}$ and a length of 4.0 $\mathrm{cm}$, the total surface area of the GO sheet is $A_{G O-\text { sheet }}=2 \pi r L=6.28 \times 10^{-4} \mathrm{~m}^{2}$. Putting all those numbers into Equation (1), the total number of GO sheets in our cylindrical probe surface is approximately $7.63 \times 10^{13}$ GO sheets. Due to a space limitation, each GO sheet can't interact with a single SGCoV. The diameter of SARS-CoV-2 is observed experimentally around $D=100$ $\mathrm{nm}$ [51], so the restricted area occupied by a single SARS-CoV-2 is $A_{c o v}=D^{2}=10,000 \mathrm{~nm}^{2}$. The maximum number of SARS-CoV-2 that can be adsorbed by GO sheet then reduced to

$$
N_{\max -\mathrm{cov}}=\frac{A_{G O-\text { sheet }}}{A_{\mathrm{cov}}}
$$

From Equation (2), it is found that $N_{\text {max-cov }}$ approximately $6.28 \times 10^{10}$ viruses. This value is close to the number of viruses expected from the human's sputum $\left(\approx 10^{6}\right.$ to $10^{11}$ viruses $)$ reported by [51]. The space-limited geometry model of virus counting is illustrated in Figure 4. 
The docking simulation found that the best binding affinity of SGCoV on GO sheet is $-12.3 \mathrm{kcal} / \mathrm{mol}$. This binding affinity can be converted into the value of binding energy of each SGCoV-GO complex, $E_{b v}$, by using this relation below

$$
E_{b v}=\frac{\Delta G}{N_{A}}
$$

Putting the values of each parameter into Equation (3), and by converting the unit of calorie into Joule $(1.0 \mathrm{cal}$ equal to $4.184 \mathrm{~J})$, we obtained the value of binding energy of each SGCoV-GO complex, $E_{b v}=8.55 \times 10^{-20} \mathrm{~J} /$ virus (about $0.534 \mathrm{eV} /$ virus).

The total energy needed to dissociate all adsorbed SARS-CoV-2 from the GO surface (to break the SGCoV-GO complex), $E_{\text {tot-dis }}$ is

$$
E_{\text {tot-dis }}=E_{b v} \cdot N_{\max -\mathrm{cov}}
$$

For our case above $\left(N_{\text {max }}\right.$-cov $=6.28 \times 10^{10}$ viruses), the total dissipated energy needed to dissociate all adsorbed viruses is $E_{\text {tot-dis }}=5.37 \times 10^{-9} \mathrm{~J}$. Considering the thermal properties of GO, i.e., the specific heat of $C_{G O}$ around $710 \mathrm{~J} / \mathrm{kg} . \mathrm{K}[52,53]$. This total dissociation energy corresponds to the minimum temperature increase needed to dissociate all adsorbed SARS$\mathrm{CoV}-2$ from the surface of the GO-coated probe $\left(\Delta T_{d i s}\right)$, expressed by

$$
\Delta T_{d i s}=\frac{E_{t o t-d i s s}}{m_{t o t G O} \cdot C_{G O}}
$$

Where the total mass of GO coated on the cylindrical probe $\left(m_{t o t G O}\right)$ is :

$$
m_{\text {totGO }}=\frac{n_{\text {layer }} \cdot A_{G O-\text { sheet }}}{\beta}
$$

If we only consider surface heating (for example, by irradiation or light illumination), $n_{\text {layer }}=1, A_{G O-\text { sheet }}=6.28 \times 10^{-4} \mathrm{~m}^{2}$ and $\beta=2418 \mathrm{~m}^{2} / \mathrm{g}$, the change of temperature needed to dissociate all the adsorbed SARS-CoV-2 is

$$
\Delta T_{\text {dis }}=\frac{E_{\text {tot-diss }} \beta}{n_{\text {layer }} \cdot A_{G O-\text { sheet }} \cdot C_{G O}}
$$

Calculation of Equation (7) produces the minimum temperature change needed to dissociate all SGCoV-GO from the GO surface, $\Delta T_{d i s}=2.91 \times 10^{-2} \mathrm{~K}$. Of course, if we take into account the thickness of the GO-sheet, we need to use the proper number of GO-sheet layer. Assuming the thickness of a single layer of GO is $1.0 \mathrm{~nm}$, a typical 100 to 1000 layers of GO ( 0.1 to $1.0 \mu \mathrm{m}$ thickness) is deposited in the real device and produces a smaller $\Delta T_{\text {dis. }}$.

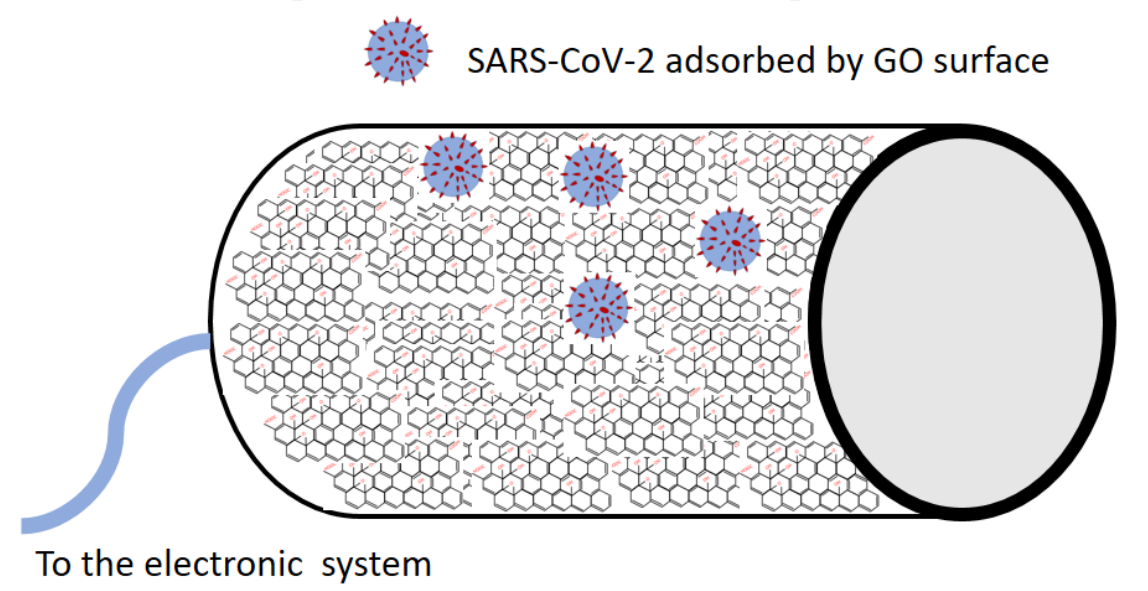

Figure 3. The illustration of SARS-CoV-2 adsorption by a GO-coated cylindrical probe. 
The fact that $T_{d i s}$ is quite small allows us to expect that small heating of the probe (by electrical or optical means) will destroy all adsorbed SARS-CoV-2. In that case, the GO sheet is utilized as the hotbed for virus destruction by transferring the thermal energy to the spike glycoprotein. Increasing the electrical current flowing in the probe or irradiating the GO surface with a small powered infrared (IR) laser within the safety level can potentially destroy the trapped SARS-CoV-2.

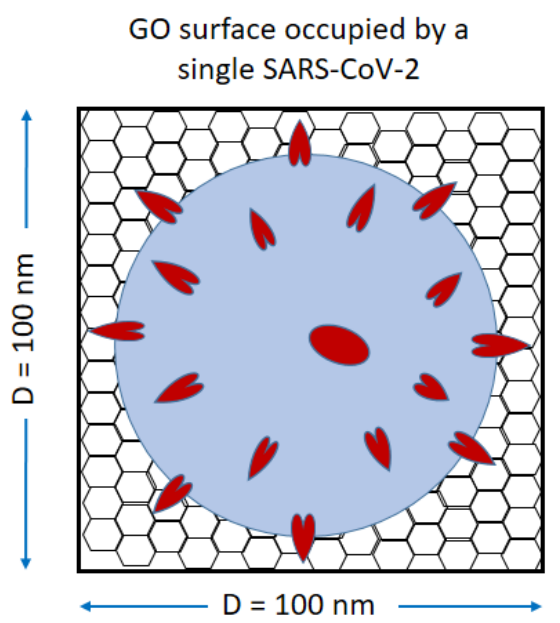

Unoccupied GO surface

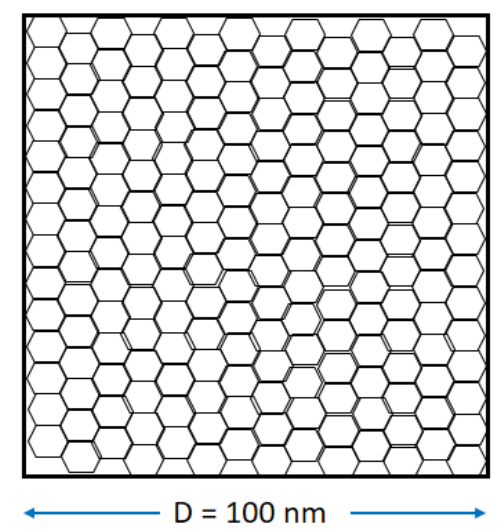

Figure 4. The illustration of a space-limited geometry model of counting the number of adsorbed SARS-CoV-2 on the GO surface.

\subsection{A thermal-based model of SARS-CoV-2 destruction by irradiation.}

The accumulation of thermal energy on the nanostructure surface (such as graphenes, gold nanoparticles or silver nanoparticles) from irradiation exposure is commonly used in the Surface Plasmon Resonance (SPR) method is capable of destroying the cancer cell via photothermal therapy. Using the same reason here, we proposed using optical means to destroy the SARS-CoV-2, which is trapped (adsorbed) on the GO-sheet. The open-air SARS-CoV-2 virus reportedly can be destroyed by UV light illumination in the range of 200 to $300 \mathrm{~nm}$ wavelength $[54,55]$. Of course, this UVC radiation is not safe to be applied directly to the body since it can ignite skin cancer. The use of a longer wavelength in the visible or IR spectrum might work, but a direct illumination of IR radiation from outside the body will not be effective due to a significant energy loss by the skin and other tissues before reaching the internal organ (throat or lung). The use of the IR spectrum inside the body is deemed quite safe and will not damage the cells. The GO-polymer composite system exposed to the IR spectrum of 800 to $1000 \mathrm{~nm}$ has been used in photothermal therapy for destroying the virus as reported by [29, $35]$.

Using, for example, the UVC wavelength of $\lambda_{U V C}=222 \mathrm{~nm}$ [56] as a minimum wavelength for SARS-CoV-2 destruction, we can calculate the minimum total energy needed to destroy all adsorbed virus, similar to Equation (4) as

$$
E_{\text {tot-dest }}=\frac{N_{\mathrm{cov}} \cdot h \cdot c}{\lambda_{U V C}}
$$

The minimum energy to destroy the adsorbed SARS-CoV-2, Etot-dest is found to be $5.62 \times 10^{-8} \mathrm{~J}$. Similar to Equation (7), we can now calculate the minimum heating (temperature change) of GO sheet needed to destroy the adsorbed SARS-CoV-2, $\Delta T_{\text {dest }}$ 


$$
\Delta T_{\text {dest }}=\frac{E_{\text {tot-dest }} \cdot \beta}{n_{\text {layer }} \cdot A_{G O-\text { sheet }} \cdot C_{G O}}
$$

By considering a surface heating only (nlayer $=1)$, then $\Delta T_{\text {dest }}=0.305 \mathrm{~K}$. This result suggests that only the GO-sheet's small heating is needed to destroy the adsorbed SARS-CoV2.

Considering the same cylindrical-shaped GO probe as in the previous sub-section, but now combined with optical devices such as a small powered IR laser or LED, we can build the physical model for SARS-CoV-2 destruction the optical mean (see Figure 5(a)). Under an ideal condition, the amount of radiation energy received (absorbed) by the SGCoV-GO complex due to electromagnetic radiation $(Q)$ can be calculated by

$$
Q=\frac{h \cdot c}{\lambda}
$$

Assuming a one by one interaction between a single SGCoV-GO complex and a single photon (where $m_{G O}$ refer to the mass of a single GO sheet), then the temperature change of a single GO sheet due to single-photon irradiation becomes

$$
\Delta T=\frac{h c}{\lambda \cdot m_{G O} \cdot C_{G O}}
$$

The mass of a single GO sheet $\left(m_{G O}\right)$ is $3.40 \times 10^{-24} \mathrm{~kg}$ (this value can be derived from its molecular weight). If we use IR irradiation with $\lambda=800 \mathrm{~nm}$, then the temperature change due to the heat accumulation in a local site of a single GO sheet is $102.9 \mathrm{~K}$. Off course, this temperature is rather high, but keeping that in mind that this number is a purely theoretical approach under the ideal condition and also neglecting other possible technical factors. The real temperature increase of GO sheet due to IR irradiation could be smaller. As a comparison, the temperature increase obtained by nano-GO irradiated by a low power laser with $808 \mathrm{~nm}$ wavelength and $0.6 \mathrm{~W} / \mathrm{cm}^{2}$ of intensity for 8 minutes is $35 \mathrm{~K}$, while nano-reduced graphene oxide could reach $55^{\circ} \mathrm{C}$ and be aimed to destroy the cancer cells [29].

Consider the GO surface's irradiation by a small powered IR laser with the pulse frequency of $f_{\text {laser }}$ and the intensity $I$. The increasing temperature of the GO surface due to IR irradiation can be calculated through this Equation:

$$
\Delta T=\frac{I \cdot A}{m_{t o t G O} \cdot C_{G O} \cdot f_{\text {laser }}}
$$

Assuming the intensity of the laser $0.1 \mathrm{~W} / \mathrm{cm}^{2}$, the frequency of the laser's pulse is 100 $\mathrm{KHz}$, the total mass of GO deposited on the surface of the cylindrical probe (nlayer $=1)$ is $m_{t o t} G O=2.60 \times 10^{-10} \mathrm{~kg}$, then plugging all the required data in the Equation (12), we found $\Delta T=34$ $\mathrm{K}$ and enough to destroy the adsorbed SARS-CoV-2. If we consider the heating of the entire layer of GO deposited on the cylindrical probe, then the temperature change $\Delta T$ is reduced by a factor of $n$ (the number of the GO layer). In the above case, $\Delta T=0.34 \mathrm{~K}$ when the thickness of GO sheet is $100 \mathrm{~nm}$ ( $n=100$ layers and assuming the thickness of a single GO sheet is 1.0 $\mathrm{nm})$.

One possible application of the GO-coated cylindrical probe is a swab-test-like probe inserted through a nasal (or throat) way, as illustrated in Figure 5(b). This hypothetical device might be used in a similar way to a regular nasopharyngeal swab test. Instead of taking the nasopharyngeal swab specimen, this GO-coated probe can be used for COVID-19 treatment by facilitating the adsorption and destruction of SARS-CoV-2 through surface heating, either 
by electrical heating, IR irradiation, or other thermal sources. Another hypothetical design of the possible medical device for destroying the SARS-CoV-2 is the GO-coated catheter wire equipped with a small powered IR laser (or LED) for drainage of pleural effusion-like treatment (see Figure 5(c)). This moderate invasive treatment through the lung might be used for patients with the worst condition in the advanced stage of COVID-19. The relatively small amount of thermal or optical energy needed to destroy the SARS-CoV-2 trapped on the GO surface as proposed in this model (Equation (7), (9), and (12)) hopefully ensures the safety and the effectiveness of this proposed design of GO-based medical device.

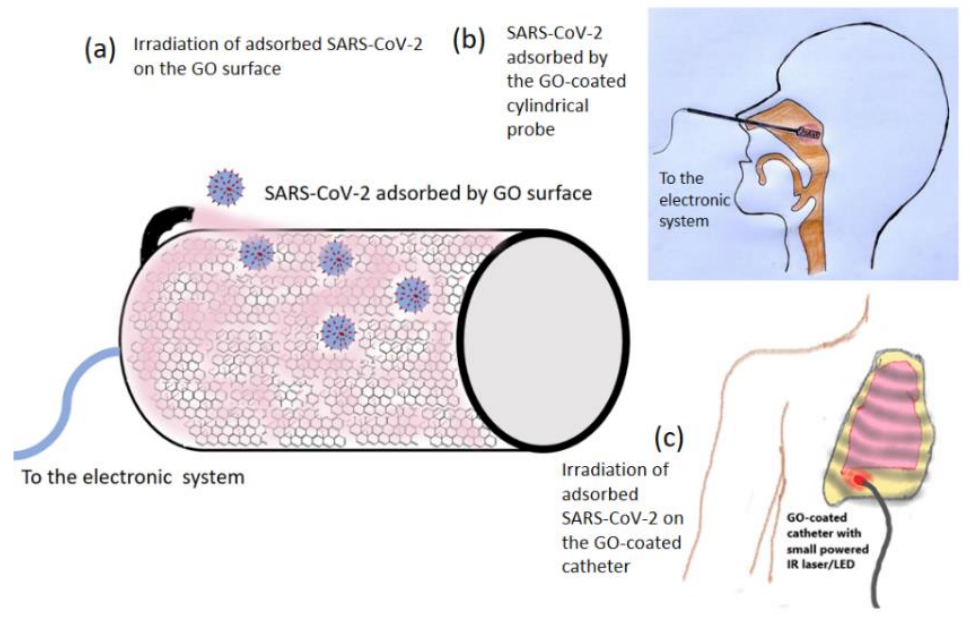

Figure 5. (a) The proposed GO-coated cylindrical hotbed is equipped with a small powered infrared laser or an electrical heating system. (b) A possible medical device's hypothetical design for destroying the SARS-CoV-2 is a swab-test-like probe equipped with an electrical or optical heating system. (c) the GO-coated catheter wire equipped with a small powered IR laser or an electrical heating system for the drainage of pleural effusion-like treatment. Note that the picture just for illustration and not for the actual size, color, and device system.

\section{Conclusions}

The possibility of SARS-CoV-2 destruction using the GO sheet's thermal response has been demonstrated in a proposed thermal-based model. The space-limited geometry model set up the maximum limit of the number of SARS-CoV-2 that can be absorbed on a particular surface area of GO. Having this limit and by utilizing the thermal properties of GO, a thermalbased model was built to estimate the minimum energy required to destroy the viruses either by thermal or optical means. This simplified model can serve as a physical basis for further developing a medical device for rapid and effective destruction of SARS-CoV-2. The proposed thermal-based model and design of the medical device still offer plenty of room for improvement. Further development and enrichment of the model by taking into account more accurate pictures of the mesoscopic realm and other physical properties of GO will improve this model.

\section{Funding}

This research received no external funding.

\section{Acknowledgments}

The authors express gratitude for the computational support from the Department of Physics, IPB University. 


\section{Conflicts of Interest}

The author declares that there is no competing interest in this work.

\section{References}

1. Colson, P.; Rolain, J.M.; Lagier, J.C.; Brouqui, P.; Raoult, D. Chloroquine and Hydroxychloroquine as Available Weapons to Fight COVID-19. International Journal of Antimicrobial Agents 2020, 55, https://doi.org/10.1016/j.ijantimicag.2020.105932.

2. Devaux, C.A.; Rolain, J.M.; Colson, P.; Raoult, D. New Insights on the Antiviral Effects of Chloroquine against Coronavirus: What to Expect for COVID-19? Int. J. Antimicrob. Agents 2020, 55, https://doi.org/10.1016/j.ijantimicag.2020.105938.

3. Al-Masoudi, N.A.; Elias, R. S.; Saeed, B. Molecular Docking Studies of Some Antiviral and Antimalarial Drugs via Bindings to 3cl-Protease and Polymerase Enzymes of the Novel Coronavirus (Sars-Cov-2). Biointerface Res. Appl. Chem. 2020, 10, 6444-6459, https://doi.org/10.33263/BRIAC105.64446459.

4. Wang, M.; Cao, R.; Zhang, L.; Yang, X.; Liu, J.; Xu, M.; Shi, Z.; Hu, Z.; Zhong, W.; Xiao, G. Remdesivir and Chloroquine Effectively Inhibit the Recently Emerged Novel Coronavirus (2019-NCoV) in Vitro. Cell Research 2020, 30, 269-271, https://doi.org/10.1038/s41422-020-0282-0.

5. Baron, S.; Devaux, C.; Colson, P.; Al, E. Teicoplanin: An Alternative Drug for the Treatment of COVID19 ? Int. J. Antimicrob. Agents 2020, 55, https://doi.org/10.1016/j.ijantimicag.2020.105944.

6. Zhou, P.; Yang, X.-L.; Wang, X.-G.; Hu, B.; Zhang, L.; Zhang, W.; Si, H.-R.; Zhu, Y.; Li, B.; Huang, C.L.; Chen, H.-D.; Chen, J.; Luo, Y.; Guo, H.; Jiang, R.-D.; Liu, M.-Q.; Chen, Y.; Shen, X.-R.; Wang, X.; Zheng, X.-S.; Zhao, K.; Chen, Q.-J.; Deng, F.; Liu, L.-L.; Yan, B.; Zhan, F.-X.; Wang, Y.-Y.; Xiao, G.-F.; Shi, Z.-L. A Pneumonia Outbreak Associated with a New Coronavirus of Probable Bat Origin. Nature 2020, https://doi.org/10.1038/s41586-020-2012-7.

7. Song, P.; Karako, T. COVID-19: Real-Time Dissemination of Scientific Information to Fight a Public Health Emergency of International Concern. Biosci. Trends 2020, 14, 1-2, https://doi.org/10.5582/BST.2020.01056.

8. Sumaryada, T.; Pramudita, C.A. Molecular Docking Evaluation of Some Indonesian's Popular Herbals for a Possible Covid-19 Treatment. Biointerface Res. Appl. Chem. 2021, 11, 9827-9835, https://doi.org/10.33263/BRIAC113.98279835.

9. Ajeet; Aggarwal, B.; Verma, S.K. Favipiravir May Acts as Covid-19 Main Protease Pdb Id 6lu7 Inhibitor: Docking Analysis. Biointerface Res. Appl. Chem. 2020, 10, 6821-6828, https://doi.org/10.33263/BRIAC106.68216828.

10. Wrapp, D.; Wang, N.; Corbett, K.S.; Goldsmith, J.A.; Hsieh, C.L.; Abiona, O.; Graham, B.S.; McLellan, J.S. Cryo-EM Structure of the 2019-NCoV Spike in the Prefusion Conformation. Science 2020, 367, 12601263, https://doi.org/10.1126/science.abb2507.

11. Hoffmann, M.; Kleine-Weber, H.; Schroeder, S.; Krüger, N.; Herrler, T.; Erichsen, S.; Schiergens, T.S.; Herrler, G.; Wu, N.-H.; Nitsche, A.; Müller, M.A.; Drosten, C.; Pöhlmann, S. SARS-CoV-2 Cell Entry Depends on ACE2 and TMPRSS2 and Is Blocked by a Clinically Proven Protease Inhibitor. Cell 2020, 181, 271-280.e8, https://doi.org/10.1016/j.cell.2020.02.052.

12. Monteil, V.; Kwon, H.; Prado, P.; Hagelkrüys, A.; Wimmer, R.A.; Stahl, M.; Leopoldi, A.; Garreta, E.; Hurtado del Pozo, C.; Prosper, F.; Romero, J.P.; Wirnsberger, G.; Zhang, H.; Slutsky, A.S.; Conder, R.; Montserrat, N.; Mirazimi, A.; Penninger, J.M. Inhibition of SARS-CoV-2 Infections in Engineered Human Tissues Using Clinical-Grade Soluble Human ACE2. Cell 2020, 181, 905-913.e7, https://doi.org/10.1016/j.cell.2020.04.004.

13. Liu, Z.; Xiao, X.; Wei, X.; Li, J.; Yang, J.; Tan, H.; Zhu, J.; Zhang, Q.; Wu, J.; Liu, L. Composition and Divergence of Coronavirus Spike Proteins and Host ACE2 Receptors Predict Potential Intermediate Hosts of SARS-CoV-2. J. Med. Virol. 2020, 1-7, https://doi.org/10.1002/jmv.25726.

14. Ahmed, S.F.; Quadeer, A.A.; McKay, M.R. Preliminary Identification of Potential Vaccine Targets for the COVID-19 Coronavirus (SARS-CoV-2) Based on SARS-CoV Immunological Studies. Viruses 2020, 12, https://doi.org/10.3390/v12030254.

15. Pandey, P.; Khan, F.; Rana, A. K.; Srivastava, Y.; Jha, S.K.; Jha, N.K. A Drug Repurposing Approach towards Elucidating the Potential of Flavonoids as Covid-19 Spike Protein Inhibitors. Biointerface Res. Appl. Chem.2021, 11, 8482-8501, https://doi.org/10.33263/BRIAC111.84828501.

16. Novoselov, K.S.; Geim, A.K.; Morozov, S.V.; Jiang, D.; Zhang, Y.; Dubonos, S.V.; Grigorieva, I.V.; Firsov, A.A. Electric Field Effect in Atomically Thin Carbon Films. Science 2004, 306, 666-669, https://doi.org/10.1126/science.1102896.

17. Geim, A.K.; Novoselov, K.S. The Rise of Graphene. Nat. Mater. 2007, 6, 183-191, https://doi.org/10.1038/nmat1849.

18. Zhang, Y.; Tan, Y.W.; Stormer, H.L.; Kim, P. Experimental Observation of the Quantum Hall Effect and Berry's Phase in Graphene. Nature 2005, 438, 201-204, https://doi.org/10.1038/nature04235. 
19. Huang, X.; Yin, Z.; Wu, S.; Qi, X.; He, Q.; Zhang, Q.; Yan, Q.; Boey, F.; Zhang, H. Graphene-Based Materials: Synthesis, Characterization, Properties, and Applications. Small 2011, 1876-1902, https://doi.org/10.1002/smll.201002009.

20. Jo, G.; Choe, M.; Lee, S.; Park, W.; Kahng, Y.H.; Lee, T. The Application of Graphene as Electrodes in Electrical and Optical Devices. Nanotechnology 2012, 23, https://doi.org/10.1088/0957-4484/23/11/112001.

21. Balandin, A. A.; Ghosh, S.; Bao, W.; Calizo, I.; Teweldebrhan, D.; Miao, F.; Lau, C. N. Superior Thermal Conductivity of Single-Layer Graphene. Nano Lett. 2008, 8, 902-907, https://doi.org/10.1021/n10731872.

22. Bonaccorso, F.; Sun, Z.; Hasan, T.; Ferrari, A.C. Graphene Photonics and Optoelectronics. Nat. Photonics 2010, 4, 611-622, https://doi.org/10.1038/nphoton.2010.186.

23. Chung, C.; Kim, Y.K.; Shin, D.; Ryoo, S.R.; Hong, B.H.; Min, D.H. Biomedical Applications of Graphene and Graphene Oxide. Acc. Chem. Res. 2013, 46, 2211-2224, https://doi.org/10.1021/ar300159f.

24. Badry, R.; Radwan, S. H.; Ezzat, D.; Ezzat, H.; Elhaes, H.; Ibrahim, M. Study of the Electronic Properties of Graphene Oxide/(Pani/Teflon). Biointerface Res. Appl. Chem. 2020, 10, 6926-6935, https://doi.org/10.33263/BRIAC106.69266935.

25. Faisal, N. Mechanical Behavior of Nano-Scaled Graphene Oxide Reinforced High-Density Polymer Ethylene for Orthopedic Implants. Biointerface Res. Appl. Chem. 2020, 10, 7223-7233, https://doi.org/10.33263/BRIAC106.72237233.

26. Sumaryada, T.; Sandy Gunawan, M.; Perdana, S.; Arjo, S.; Maddu, A. A Molecular Interaction Analysis Reveals the Possible Roles of Graphene Oxide in a Glucose Biosensor. Biosensors 2019, 9, https://doi.org/10.3390/bios9010018.

27. Losada-Garcia, N.; Rodriguez-Oliva, I.; Simovic, M.; Bezbradica, D.I.; Palomo, J.M. New Advances in Fabrication of Graphene Glyconanomaterials for Application in Therapy and Diagnosis. ACS Omega 2020, 5, 4362-4369, https://doi.org/10.1021/acsomega.9b04332.

28. Lim, D.K.; Barhoumi, A.; Wylie, R.G.; Reznor, G.; Langer, R.S.; Kohane, D.S. Enhanced Photothermal Effect of Plasmonic Nanoparticles Coated with Reduced Graphene Oxide. Nano Lett. 2013, 13, 4075-4079, https://doi.org/10.1021/nl4014315.

29. Robinson, J.T.; Tabakman, S.M.; Liang, Y.; Wang, H.; Sanchez Casalongue, H.; Vinh, D.; Dai, H. Ultrasmall Reduced Graphene Oxide with High Near-Infrared Absorbance for Photothermal Therapy. J. Am. Chem. Soc. 2011, 133, 6825-6831, https://doi.org/10.1021/ja2010175.

30. Liu, J.; Cui, L.; Losic, D. Graphene and Graphene Oxide as New Nanocarriers for Drug Delivery Applications. Acta Biomaterialia 2013, 9, 9243-9257, https://doi.org/10.1016/j.actbio.2013.08.016.

31. Yousefi, M.; Dadashpour, M.; Hejazi, M.; Hasanzadeh, M.; Behnam, B.; de la Guardia, M.; Shadjou, N.; Mokhtarzadeh, A. Anti-Bacterial Activity of Graphene Oxide as a New Weapon Nanomaterial to Combat Multidrug-Resistance Bacteria. Materials Science and Engineering $C$ 2017, 74, 568-581, https://doi.org/10.1016/j.msec.2016.12.125.

32. Chen, L.; Liang, J. An Overview of Functional Nanoparticles as Novel Emerging Antiviral Therapeutic Agents. Materials Science and Engineering C. 2020, 112, https://doi.org/10.1016/j.msec.2020.110924.

33. Chen, Y.N.; Hsueh, Y.H.; Hsieh, C.Te; Tzou, D.Y.; Chang, P.L. Antiviral Activity of Graphene-Silver Nanocomposites against Non-Enveloped and Enveloped Viruses. Int. J. Environ. Res. Public Health. 2016, 13, https://doi.org/10.3390/ijerph13040430.

34. Ye, S.; Shao, K.; Li, Z.; Guo, N.; Zuo, Y.; Li, Q.; Lu, Z.; Chen, L.; He, Q.; Han, H. Antiviral Activity of Graphene Oxide: How Sharp Edged Structure and Charge Matter. ACS Appl. Mater. Interface 2015, 7, 21578-21579, https://doi.org/10.1021/acsami.5b06876.

35. Deokar, A.R.; Nagvenkar, A P.; Kalt, I.; Shani, L.; Yeshurun, Y.; Gedanken, A.; Sarid, R. Graphene-Based "Hot Plate" for the Capture and Destruction of the Herpes Simplex Virus Type 1. Bioconjug. Chem. 2017, 28, 1115-1122, https://doi.org/10.1021/acs.bioconjchem.7b00030.

36. Du, T.; Lu, J.; Liu, L.; Dong, N.; Fang, L.; Xiao, S.; Han, H. Antiviral Activity of Graphene Oxide-Silver Nanocomposites by Preventing Viral Entry and Activation of the Antiviral Innate Immune Response. ACS Appl. Bio Mater. 2018, 1, 1286-1293, https://doi.org/10.1021/acsabm.8b00154.

37. Mao, S.; Lu, G.; Yu, K.; Bo, Z.; Chen, J. Specific Protein Detection Using Thermally Reduced Graphene Oxide Sheet Decorated with Gold Nanoparticle-Antibody Conjugates. Adv. Mater. 2010, 22, 3521-3526, https://doi.org/10.1002/adma.201000520.

38. Sametband, M.; Kalt, I.; Gedanken, A.; Sarid, R. Herpes Simplex Virus Type-1 Attachment Inhibition by Functionalized Graphene Oxide. ACS Appl. Mater. Interfaces. 2014, 6, 1228-1235, https://doi.org/10.1021/am405040z.

39. Muthoosamy, K.; Bai, R.; Manickam, S. Graphene and Graphene Oxide as a Docking Station for Modern Drug Delivery System. Curr. Drug Deliv. 2014, 11, 701-718, https://doi.org/10.2174/1567201811666140605151600.

40. Zor, E.; Morales-Narváez, E.; Alpaydin, S.; Bingol, H.; Ersoz, M.; Merkoçi, A. Graphene-Based Hybrid for Enantioselective Sensing Applications. Biosens. Bioelectron. 2017, 87, 410-416, https://doi.org/10.1016/j.bios.2016.08.074. 
41. Rathinam, N.K.; Saravanan, C.; Parimal, P.; Perumal, V.; Perumal, M. Molecular Interactions of Graphene with HIV-Vpr, Nef and Gag Proteins: A New Approach for Treating HIV Infections. Korean J. Chem. Eng. 2014, 31, 744-747, https://doi.org/10.1007/s11814-014-0049-8.

42. Benyamini, H.; Shulman-Peleg, A.; Wolfson, H.J.; Belgorodsky, B.; Fadeev, L.; Gozin, M. Interaction of C60-Fullerene and Carboxyfullerene with Proteins: Docking and Binding Site Alignment. Bioconjug. Chem. 2006, 17, 378-386, https://doi.org/10.1021/bc050299g.

43. Tyagi, P.K.; Tyagi, S.; Kumar, A.; Ahuja, A.; Gola, D. Contribution of Nanotechnology in the Fight against Covid-19. Biointerface Research in Applied Chemistry 2021, 11, 8233-8241, https://doi.org/10.33263/BRIAC111.82338241.

44. Palmieri, V.; Papi, M. Can Graphene Take Part in the Fight against COVID-19? Nano Today. 2020, 33, https://doi.org/10.1016/j.nantod.2020.100883.

45. Pettersen, E.F.; Goddard, T.D.; Huang, C.C.; Couch, G.S.; Greenblatt, D.M.; Meng, E.C.; Ferrin, T.E. UCSF Chimera - A Visualization System for Exploratory Research and Analysis. J. Comput. Chem. 2004, 25, 1605-1612, https://doi.org/10.1002/jcc.20084.

46. Morris, G.M.; Ruth, H.; Lindstrom, W.; Sanner, M.F.; Belew, R.K.; Goodsell, D.S.; Olson, A.J. Software News and Updates AutoDock4 and AutoDockTools4: Automated Docking with Selective Receptor Flexibility. J. Comput. Chem. 2009, 30, 2785-2791, https://doi.org/10.1002/jcc.21256.

47. Trott, O.; Olson, A.J. AutoDock Vina: Improving the Speed and Accuracy of Docking with a New Scoring Function, Efficient Optimization, and Multithreading. J. Comput. Chem. 2010, https://doi.org/10.1002/jcc.21334.

48. Li, Y.; Yuan, H.; Von Dem Bussche, A.; Creighton, M.; Hurt, R.H.; Kane, A.B.; Gao, H. Graphene Microsheets Enter Cells through Spontaneous Membrane Penetration at Edge Asperities and Corner Sites. Proc. Natl. Acad. Sci. U. S. A. 2013, 110, 12295-12300, https://doi.org/10.1073/pnas.1222276110.

49. Ryu, S.; Kwon, Y.J.; Kim, Y.; Lee, J.U. Corrosion Protection Coating of Three-Dimensional Metal Structure by Electrophoretic Deposition of Graphene Oxide. Mater. Chem. Phys. 2020, 250, https://doi.org/10.1016/j.matchemphys.2020.123039.

50. Zhang, S.; Wang, H.; Liu, J.; Bao, C. Measuring the Specific Surface Area of Monolayer Graphene Oxide in Water. Mater. Lett. 2020, 261, https://doi.org/10.1016/j.matlet.2019.127098.

51. Bar-On, Y. M.; Flamholz, A.; Phillips, R.; Milo, R. Sars-Cov-2 (Covid-19) by the Numbers. Elife 2020, 9 , https://doi.org/10.7554/eLife.57309.

52. Pop, E.; Varshney, V.; Roy, A.K. Thermal properties of graphene: Fundamentals and applications. MRS Bull 2012, 37, 1273-1281, https://doi.org/10.1557/mrs.2012.203.

53. Koh, Y.K.; Bae, M.H.; Cahill, D.G.; Pop, E. Heat Conduction across Monolayer and Few-Layer Graphenes. Nano Lett. 2010, 10, 4363-4368, https://doi.org/10.1021/nl101790k.

54. Yin, R.; Dai, T.; Avci, P.; Jorge, A.E.S.; de Melo, W.C.M.A.; Vecchio, D.; Huang, Y.-Y.; Gupta, A.; Hamblin, M.R. Light Based Anti-Infectives: Ultraviolet C Irradiation, Photodynamic Therapy, Blue Light, and Beyond. Curr. Opin. Pharmacol. 2013, 13, 731-762, https://doi.org/10.1016/j.coph.2013.08.009.

55. Buonanno, M.; Ponnaiya, B.; Welch, D.; Stanislauskas, M.; Randers-Pehrson, G.; Smilenov, L.; Lowy, F.D.; Owens, D.M.; Brenner, D.J. Germicidal Efficacy and Mammalian Skin Safety of 222-Nm UV Light. Radiat. Res. 2017, 187, https://doi.org/10.1667/RR0010CC.1.

56. Woods, J.A.; Evans, A.; Forbes, P.D.; Coates, P.J.; Gardner, J.; Valentine, R.M.; Ibbotson, S.H.; Ferguson, J.; Fricker, C.; Moseley, H. The Effect of 222-Nm UVC Phototesting on Healthy Volunteer Skin: A Pilot Study. Photodermatol. Photoimmunol. Photomed. 2015, 31, 159-166, https://doi.org/10.1111/phpp.12156. 